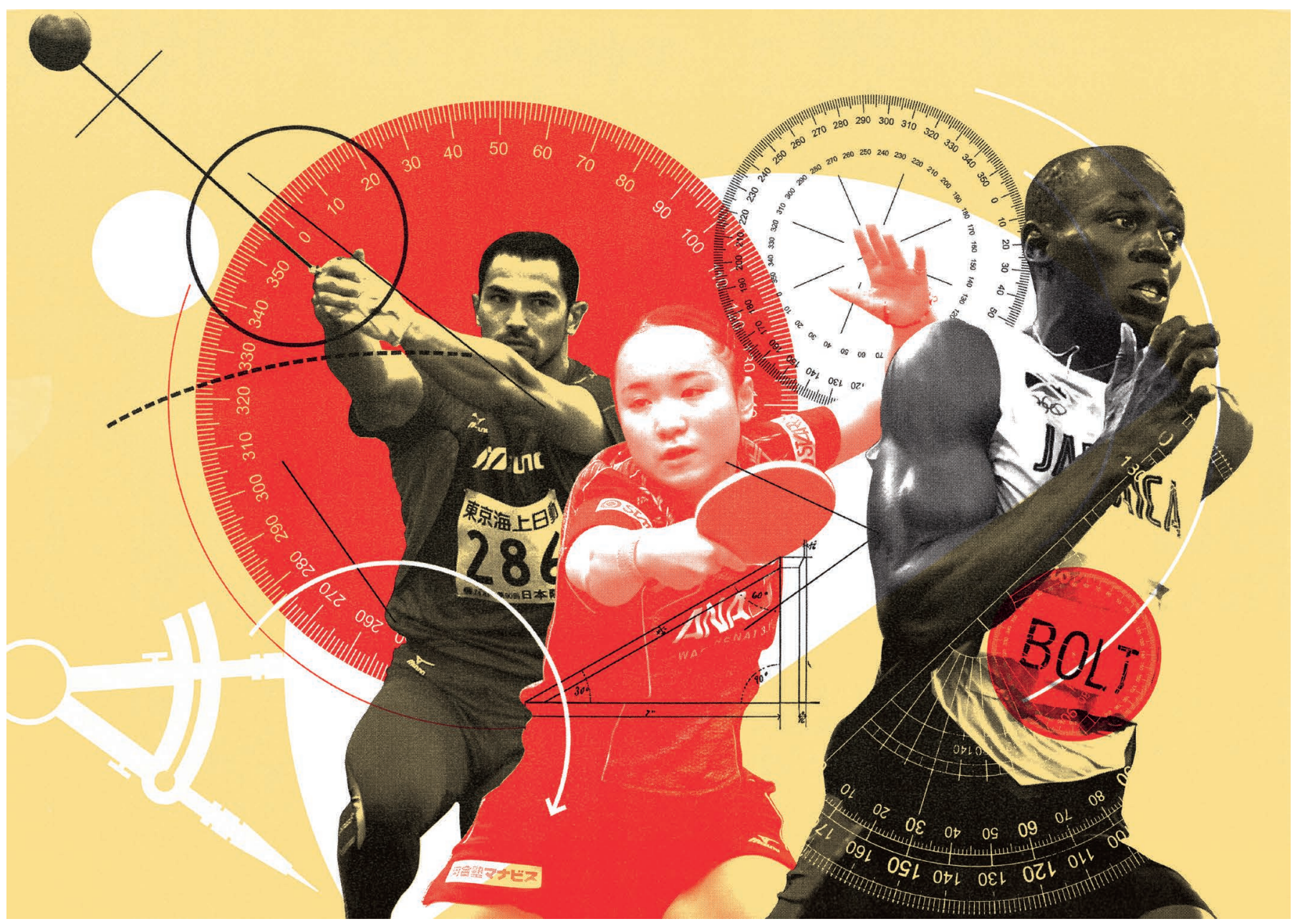

\title{
Smarter, not harder
}

\section{The young discipline of sports science is finding ways to stretch the boundaries of human biology.}

BY TIM HORNYAK

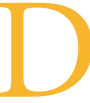
espite his loss and subsequent retirement at the world championships in London last month, Usain Bolt still holds the record as the fastest human in history. The Jamaican was already a potent force of nature on the track, but when he sealed his unprecedented 'triple triple' at the 2016 Olympic Games in Rio de Janeiro by winning the 100 -metre, 200 -metre and $4 \times 100$-metre events for the third time, his performance was all the more astonishing. "We've never seen the likes of this, and surely we won't see it again," said one commentator at the time.

Although one of Bolt's wins at the 2008 Beijing Olympics was disqualified because of teammate Nesta Carter's doping violation, making his title a 'double triple', the sprinter's dominance has prompted a mix of both wonder and puzzlement. To understand it, commentators and the public have had to turn to science.

Sprinters face a trade-off when it comes to their physique - a taller sprinter enjoys a longer stride, which means he or she has fewer steps to take over a full race. But those longer legs take more work to move: a shorter sprinter can take his or her strides faster. This leads to a simple equilibrium between length and frequency. Most sprinters aren't as tall as you might expect - they're never much more than 6 feet $(1.83 \mathrm{~m})$.

This makes Bolt's height his most remarkable physical feature. "At $1.96 \mathrm{~m}$, Bolt is very tall and he has a big body mass of 90-93 kilograms when he competes. This gives him a long stride of $2.77 \mathrm{~m}$ in his maximal speed phase," says Antti Mero, an exercise biologist at the University of Jyväskylä in Finland and co-author of a
2013 study on Bolt's best 100-m performances (M. Krzysztof and A. Mero J. Hum. Kinetics 36, 149-160; 2013). "Even though he's tall, he also has quite a high stride rate of 4.49 strides per second. Bolt can excel due to his long stride and his rather high stride rate."

\section{SPORT AS A HEALER}

Worldwide, a boom in investment and scientific interest in sports science has moved the field forward in leaps and bounds, from a siloed subdiscipline of physiology to a shining example of the impact of translational science.

Although public grant money available to sports scientists has increased significantly over the past 20 years, the public sector is only one financial driver. Spurred on by lucrative sponsorships and a naturally competitive 
venvironment, sports and athletics institutions have invested heavily in more evidencebased approaches to their business.

An example can be found at F. C. Barcelona, the world-famous Catalan football club in Spain. In March, it unveiled its own 'innovation hub' with a declared aim of collaborating with "prestigious brands, universities, research centres, start-ups, entrepreneurs, students, athletes, investors, and visionaries around the world".

And, while researchers study what makes the best athletes so good, interest is also growing in the science behind physical activity and its benefits for everyone. The US National Institutes of Health (NIH) announced in 2015 that it will award US $\$ 170$ million over a five-year period to researchers who study molecular changes during and after exercise. The aim is to understand how physical activity affects the human body.

"Armed with this knowledge, researchers and clinicians may one day be able to define optimal physical activity recommendations for people at various stages of life, as well as develop precisely targeted regimens for individuals with particular health needs," said NIH director Francis Collins when the study was announced. In other words, exercise and its benefits will become quantifiable - something that can be prescribed, like medicine. As investigation of the medical benefits of exercise continues, sports science is gaining adherents. The United States, the United Kingdom and Japan have university departments and even entire universities dedicated to this newly rejuvenated discipline.

\section{NEW TECHNOLOGIES}

Sports science has come a long way since medical student Roger Bannister broke the four-minute mile in 1954. Not only have athletes since shaved nearly 17 seconds off those 4 minutes, they've also incorporated modern tools and analyses into their training and performance. Technologies such as artificial track surfaces and low-friction swimsuits have propelled elite runners and swimmers to new speeds, and athletic physiques are changing. Professional basketball players today, for instance, are about 10 centimetres taller than players 70 years ago.

"Sports science combines the principles of psychology, physiology and medicine along with rehabilitation and sports performance," says Juan Delgado, a sports scientist and biomechanist at the privately owned Sports Science Lab in New York City. "This unique combination gives an insight as to how the human body works before, during and after exercise."

The goal of sports science, explains Delgado, is to help athletes reach their full potential by applying a scientific approach. This helps them to address their weaknesses, "improving their strengths and reducing their chances of getting injured", he notes.

Opened in 2015, the gym-come-researchlab uses a range of technologies to help everyone from baseball players to archers and mixed martial artists. Athletes undergo a full assessment to measure body metrics and how quickly they move, as well as motion analysis, sensory motor skills, visual acuity and depth perception. To assess a runner, for instance, the analysts do a battery of tests to gauge muscle performance and whether changes should be made to training regimens.

Sensors to record muscle electrical activity are attached to the runner's body through a Hexoskin shirt, which contains an inertial measurement unit and sensors to monitor respiration and heart rate. The data can be displayed in real time alongside a 3D image of the athlete's skeleton. The lab can also test motor control, ground-force reaction and isokinetic muscular strength to help an athlete assess areas of weakness and improve their physical performance.

But there's another dimension to training. Delgado thinks that brain training, also known as neurotechnology, can enhance brain-muscle connections and produce more-efficient muscle coordination in an athletic event. One example he gives is the use of 'neuropriming' devices

\section{EACH SPORT CAN BENEFIT FROM SPORTS SCIENCE, AND EVEN USE THE SAME TECHNOLOGY IN DIFERENT WAYS.}

such as the Halo Sport, headphones that deliver electrical pulses to the scalp and brain, supposedly allowing motor-cortex neurons to build neural connections more easily. This 'neuroplastic state' is said to last about an hour after the device has been worn for 20 minutes during an athlete's warm-up. Delgado says that the device is backed by findings in more than 2,000 peerreviewed papers (see, for example, A. Bastani and S. Jaberzadeh Clin. Neurophysiol. 123, 644-657; 2012). It has reportedly helped Oakland Raiders cornerback T. J. Carrie to increase the height of his standing jump by up to $18 \mathrm{~cm}$.

"Neurotechnology combines auditory, kinetic and visual stimulus to promote neuroplasticity," Delgado says. “This whole new field of sports science gives a more comprehensive approach to the traditional exercise regimen - it gives an edge to the modern-day athlete."

When mixed martial artist Al Iaquinta came to the lab in early March 2017, he wanted to rehabilitate a slight knee injury and practise before his April bout with fellow athlete Diego Sanchez. Iaquinta used exercise equipment that included a touch-screen television to hone hand-eye coordination, and perfected his rhythm by using a sensor strapped to his palm to measure claps in time to a metronome. He also spent up to 3 minutes at a time in a nitrogen-cooled cryotherapy chamber that runs at around $-183^{\circ} \mathrm{C}$ to reduce muscle damage from training (the scientific community is in disagreement on the effectiveness of cold therapy for treating muscle damage).

Iaquinta had been out of the ring for 2 years, but 40 days after joining the lab - and 98 seconds from the opening bell - he won. "It's one of our biggest success stories," says Delgado. "This is why I think brain training is the future of sports-performance training."

\section{SCIENCE POWERING THE GAMES}

With Tokyo hosting the Summer Olympics in 2020, Japan has invested heavily in sports science. The capital plays host to two facilities designed to strengthen elite Japanese athletes: the Japan Institute of Sports Sciences (JISS), established in 2001, and the National Training Center (NTC), completed in 2008. Run by the Japan Sport Council, the two centres cost more than $\$ 620$ million, according to officials.

The JISS supports some 150 researchers in disciplines from biomechanics to psychology. It has eight floors of cutting-edge sports facilities. These range from a high-performance gym where athletes can check their posture through multi-camera angle visualization while jumping on force plates, to biomechanics and biochemistry labs. There is also a magnetic resonance imaging (MRI) chamber, as well as cryogenic recovery booths and dormitories where the oxygen level can be adjusted to prepare for competition at higher altitudes. The facilities at the neighbouring NTC are more run-of-the-mill, but they're extensive: volleyball, badminton and basketball courts; boxing rings, judo and wrestling mats; and a 25-metre-long swimming pool. Athletes from all over Japan come here to train and to consult with staff.

"We're constantly watching videos of our competitions as well as athletes we will compete against to check our weak points and theirs," says 16-year-old Mima Ito, who won a bronze medal in table tennis at the 2016 Rio Olympics. She trains in a large room at the NTC, loud with the din of ping-pong balls. When she's not practising at her club in Osaka, Ito attends training camps at the NTC, where biomechanics researchers can analyse aspects of her game, such as ball speed and spin.

"In the past, table-tennis players would train hard and their approach was, 'If there's a will, there's a way', but these days we review performances over and over to improve our chances," says Ito's NTC coach Taisuke Matsuzaki. "We're focused on strength-building and monitoring weight and diet, but I also think an athlete's environment is key for motivation."

"Each sport can benefit from sports science, and even use the same technology in different ways," says JISS researcher Mariko Nakamura, who specializes in female health and athletics. 


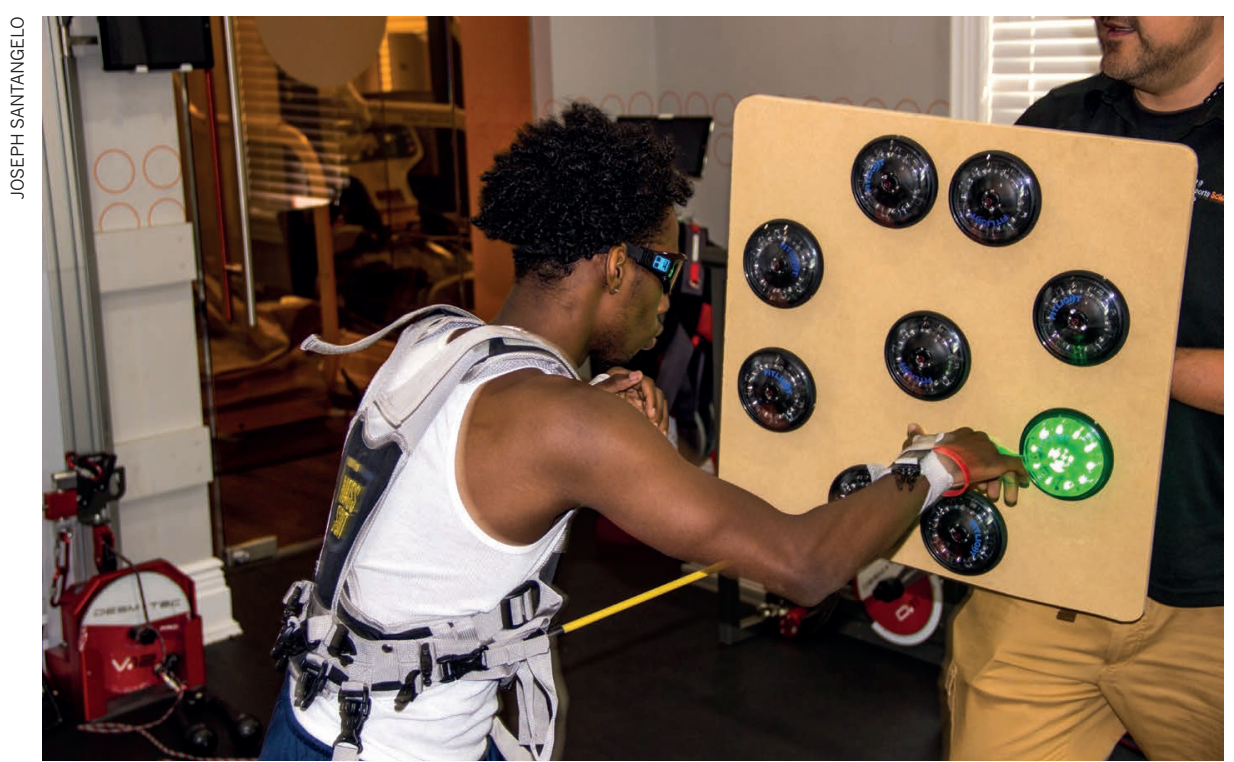

A boxer at the Sports Science Lab in New York City uses a visual-stimulus system to improve reaction time.

"When it comes to setting new world records, I think it's a question of the athlete giving it their all, as well as coaching and training. Sports science can give them a slight edge that makes an important difference."

\section{KINETICS HAMMERED HOME}

Former Olympic hammer-thrower Koji Murofushi learnt the importance of technology in sport at an early age. Murofushi's father, Shigenobu, competed in the same discipline in several Olympics, and his mother, Serafina Moritz, threw javelin for Romania.

In the 1960s, Murofushi's father would spend entire days training, doing 300 throws, only to see his performance deteriorate. When he began filming himself, however, he noticed serious errors in his form that he immediately corrected. From that experience, he insisted on filming all of his son's hammer-throw competitions and sharing the footage with him.

"As an athlete, you have a subjective sense of yourself and there's an objective sense. My father's message was that you always have to see yourself objectively," says Murofushi. "Even after I had absorbed everything he could teach me about hammer throw, he was always carrying the camera so I could see myself."

The endless playbacks paid off. Murofushi competed successfully in national and regional track-and-field tournaments. He recorded a personal best of 84.86 metres in 2003 the fourth-farthest throw in the history of the sport. He won a silver medal in the 2004 Olympics in Athens that was soon upgraded to gold after Hungarian Adrián Annus was disqualified for a doping violation. After the Games, Murofushi's interest in sports science deepened. In 2008, he completed a doctorate in physical education at Chukyo University in Nagoya, Japan.

Murofushi has explored high-tech paths to perfect hammer throws and to increase his understanding of sports science. With researchers Ken Ohta at the Institute of Systems, Information Technologies and Nanotechnologies in Fukuoka, Japan, and Yuji Ohgi at Keio University in Tokyo, he developed a prototype sensor-equipped hammer that can help to improve performance. The first versions contained electronics that would break after a single throw, but the researchers have now made the device able to withstand an impact speed of more than 29 metres per second.

The hammer has two accelerometers that can measure angular velocity, and a unit that transmits data wirelessly to a recorder, where the information is converted into sound. Depending on how fast the hammer is spun, it emits different pitches of sound for real-time feedback about the right speed and moment to release the hammer. Murofushi describes it as a potential "sixth sense" backed up by artificial intelligence that assists and teaches athletes.

In 2014, Murofushi was appointed professor at Tokyo Medical and Dental University's newly established Sports Science Organization, and director of its Sports Science Center. Apart from teaching the benefits of sports to first-year medical students at the university, he works with staff including Dice Yamaguchi, a former assistant athletics trainer with the San Antonio Spurs professional basketball team, to support athletes who are working on boosting their strength or recovering from injury.

Although Murofushi's background is in biomechanics, he thinks that sports science will benefit from including other objective disciplines such as physiology. "Any other discipline that lets you see yourself from the outside can be part of it," he says. "Science may not give you the answer to whatever challenge you're facing, but at least it will tell you what's going on."

Tim Hornyak is a freelance science and technology journalist based in Tokyo, Japan. 